\title{
Effect of silicon carbide modifiers on the physical-mechanical properties of gray cast iron and cast iron with spheroidal graphite
}

\author{
Vladimir A. Poluboyarov ${ }^{1,3}$, Anatoliy N. Cherepanov², Viktor A. Kuznetsov ${ }^{3}$, \\ Zoya A. Korotaeva ${ }^{1}$, and Alexander A. Zhdanok ${ }^{1-}$ \\ ${ }^{1}$ Institute of Solid State Chemistry and Mechanochemistry, Siberian Branch of the Russian Academy \\ of Sciences, Novosibirsk \\ ${ }^{2}$ Khristianovich Institute of Theoretical and Applied Mechanics, Siberian Branch of the Russian \\ Academy of Sciences, Novosibirsk \\ ${ }^{3}$ Novosibirsk State Technological University, Russia, Novosibirsk
}

\begin{abstract}
The influence of mechanochemically produced modifiers on the properties of cast iron at out-of-furnace modification has been studied. Short-term treatment in mechanochemical activators makes it possible to produce composite modifiers, which are wetted with iron melts, are uniformly distributed therein and effectively influence the crystallization processes. The effect of a modifier based on silicon carbide and chromium (as a protector metal) on the physical-mechanical properties of gray castiron and cast-iron with spheroidal graphite is considered. The introduction of $\mathrm{SiC}$ in the amount of 0.01-0.1 wt.\% into gray cast iron causes the formation of mainly perlitic structure and, as a consequence, an increase in strength, hardness and wear resistance. For $\mathrm{SiC}$ content $0.1 \mathrm{wt} . \%$, the tensile strength of GG- 15 samples increased by $22.7 \%$, GG- 25 by $8 \%$. The maximal increase in the hardness is observed for $\mathrm{SiC}$ concentration: for GG-15 - 0.1, for GG-25 - 0.01 wt.\%. The GG-25 sample with 0.1 wt.\% $\mathrm{SiC}$ exhibited the highest wear resistance. The introduction of $\mathrm{SiC}(0.01-$ 0.1 wt.\%) into cast iron with spheroidal graphite causes an increase in ferrite content, which promotes a substantial increase in impact viscosity and wear resistance (the highest wear resistance is observed with the introduction of $0.05 \mathrm{wt} . \% \mathrm{SiC})$.
\end{abstract}

\section{Introduction}

Foundry processes are among the most important ones in the modern industrial production. The quality of the castings produced determines the performance characteristics of many parts of machines and structural elements. The improvement of the quality of cast metal in ingots produced by continuous casting of steel, the elimination of such defects as axial porosity and liquation, chemical and structural heterogeneity, and an increase in the crystal structure dispersity are important tasks in the practice of continuous casting. For this reason,

- Corresponding author: a-zhdanok@mail.ru 
improving the structure and the set of mechanical properties of cast metal is the urgent scientific and practical task $[1,2]$.

It is possible to influence the processes of crystallization of iron and steel melts (change the size of metal grains, change the shape, size and distribution of graphite inclusions) by introducing small, specially prepared additives of substances (modifiers) that do not chemically interact with the matrix [3-5].

It has been found experimentally that the greater is the amount of nuclei per unit volume of the melt, the more crystals are formed, the smaller they are, and the higher are the mechanical properties of the metal. Moreover, in contrast to alloying, the modification does not require a large number of expensive additives and, accordingly, only slightly increases the final cost of production.

\section{Equipment and experimental technique}

The effect of silicon carbide modifiers obtained mechanochemically on the properties of gray cast iron and cast iron with spheroidal graphite was studied by us previously [6]. It was revealed that insignificant amounts of the additive, not more than $0.05 \mathrm{wt} . \% \mathrm{SiC}$, affect even low-grade cast iron GG-10 (by changing the ratio of ferrite to perlite phases, till a complete removal of the ferrite component). For GG-15, GG-25 cast iron (with SiC content 0.01-0.4 wt.\%), in addition to an increase in the amount of perlite component, thinner and shorter flaky graphite inclusions that those in non-modified sample are observed. For castiron with spheroidal graphite GGG-50 (with $0.1 \mathrm{wt} . \% \mathrm{SiC}$ ), the radius of graphite inclusions decreases, and its distribution becomes more uniform.

In the present work, the effect of silicon carbide modifiers on the physical-mechanical characteristics of cast iron of these grades will be considered.

Modifiers were obtained mechanochemically in an AGO-3 activator mill (for $60 \mathrm{~s}$, at $60 \mathrm{~g}$ ) through the joint activation of the powders of silicon carbide (grade "green 63C") and chromium (grade "PH1C") as a protector metal (the powder ratio was 1:1). Cast iron grades GG-15, GG-25, GGG-50 (in accordance with the standard DIN 1691, 1693) was modified in a ladle (the modifier in aluminum foil was placed on the bottom of the casting ladle). Metal melt was poured in cylindrical sand casting molds $30 \mathrm{~mm}$ in diameter and $250 \mathrm{~mm}$ high. The study of tensile strength was carried out using a universal servohydraulic system of the Instron 300DX type; microstructural studies were carried out with an optical microscope Carl Zeiss AxioObserver A1m; Brinell hardness was determined using a TSH-2 device with a load of $3000 \mathrm{kgf}$; for testing metals for impact strength, a Coper MT 208 tool was used. Wear tests were carried out using the MI-1M machine under the conditions of lubrication with a liquid lubricant ("LITOL-24" was used as a lubricant). The load applied to the samples was $50 \mathrm{~N}, 100 \mathrm{~N}, 150 \mathrm{~N}, 200 \mathrm{~N}$, and $300 \mathrm{~N}$, and the mass loss by the test samples was measured after each cycle.

Sample designation and the conditions of their preparation are presented in Table 1.

Table 1. Conditions of sample preparation.

\begin{tabular}{|c|c|c|c|c|c|c|c|c|c|c|c|}
\hline \multirow{2}{*}{$\begin{array}{c}\text { Cast iron } \\
\text { samples }\end{array}$} & \multicolumn{3}{|c|}{ GG-15 } & \multicolumn{4}{c|}{ GG-25 } & \multicolumn{5}{c|}{ GGG-50 } \\
\cline { 2 - 12 } & 1.1 & 1.2 & 1.3 & 2.1 & 2.2 & 2.3 & 2.4 & 3.1 & 3.2 & 3.3 & 3.4 \\
\hline $\begin{array}{c}\text { SiC content, } \\
\text { wt.\% }\end{array}$ & 0 & 0.1 & 0.4 & 0 & 0.01 & 0.05 & 0.1 & 0 & 0.01 & 0.05 & 0.1 \\
\hline
\end{tabular}




\section{Results and discussion}

Mechanical tests. Mechanical properties of gray cast iron with different SiC content are presented in Fig. 1. Tensile strength, MPa, and hardness, HB, change to different extents depending on the amount of SiC. For SiC content 0.1 wt. $\%$, the tensile strength of GG-15 samples increased by $22.7 \%$ (Fig. $1 a$ ), GG- 25 by $8 \%$ (Fig. $1 b$ ). The maximal increase in the hardness is observed for $\mathrm{SiC}$ concentration: for GG-15 - 0.1, for GG-25 - $0.01 \mathrm{wt} . \%$.
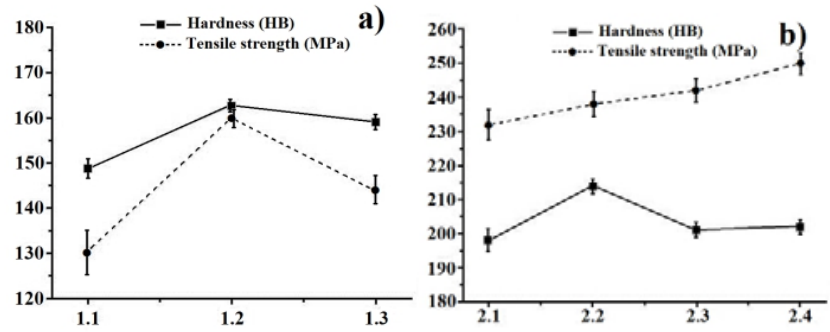

Fig. 1. Mechanical properties of gray cast iron: a) GG-15; b) GG-25.

Mechanical properties of cast iron with spheroidal graphite for different SiC content are presented in Fig. 2. The tensile strength (Fig. 2a) and hardness (Fig. 2b) of the modified GGG-50 samples inscreased insignificantly, so the strengthening effect of $\mathrm{SiC}$ on cast iron with spheroidal graphite was not so substantial as on gray cast iron. However, the shock energy, $\mathrm{J} / \mathrm{cm}^{2}$, of strengthened samples increased by $170 \%, 21 \%$ and $194 \%$, respectively (Fig. 2c), whcih points to a substantial increase in the impact viscosity of cast iron with spheroidal graphite.
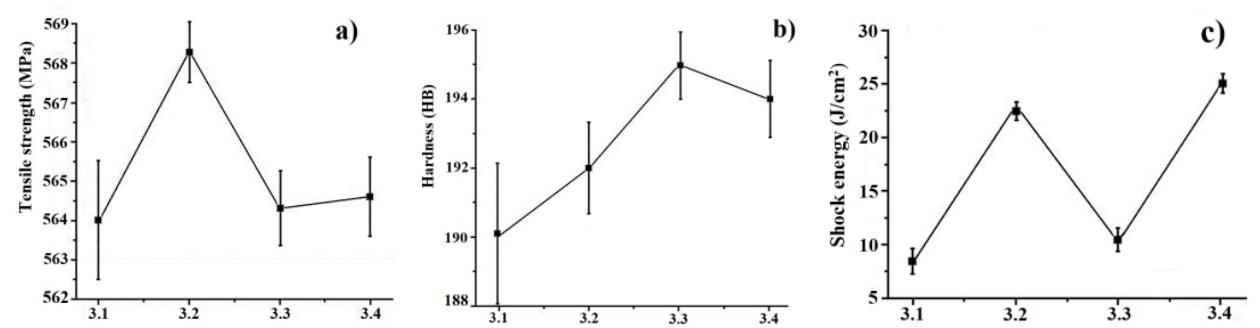

Fig. 2. Mechanical characteristics of GGG-50 for different SiC content: a) tensile strength; b) Brinell hardness; c) shock energy.

Wear resistance. Results of the investigation of cast iron wear resistance under the conditions of greasing with a liquid lubricant are presented in Fig. 3. For imposed load (50, $100,150,200,250,300 \mathrm{~N}$ ), the volume of wear, $\mathrm{cm}^{3}$, of non-modified sample 1.1 (GG-15) was the largest (Fig. $3 a)$; the volume of wear of $1.2(0.1 \mathrm{wt} . \% \mathrm{SiC})$ decreased by, $\%: 10,20$, $69,69,78$ and 71, respectively, while the data for $1.3(0.4$ wt.\% SiC) were, $\%: 33,40,77$, 75,33 and 47, respectively. Under the load less than $100 \mathrm{~N}$, all samples demonstrated the normal wear conditions. For the load reaching $150 \mathrm{~N}$, the volume of wear of sample 1.1 increased substantially. For samples 1.2 and 1.3, this phenomenon was not observed until the load reached 250 and $200 \mathrm{~N}$, respectively. Results point to the fact that the wear resistance of GG-15 increases with an increase in the amount of ultrafine $\mathrm{SiC}$ powder up to 0.4 wt. $\%$. The same improvement of wear resistance may be observed with GG-25 sample for any load (Fig. 3b). For the same material, the volume of wear increases with an increase in the load; for the same load, the volume of wear decreases with an increase in SiC content. 
Among all samples, sample 2.4 with $\mathrm{SiC}$ content 0.1 wt.\% exhibited the highest wear resistance. For any load, the volume of wear for 2.4 decreased by, \%: 80, 39, 57, 71, 71 and 59 , respectively. For GGG-50 (Fig. 3c) with the load achieving $250 \mathrm{~N}$, the volume of wear of non-modified sample 3.1 increased substantially, while strengthened materials were characterized by the best wear resistance under any load. The smallest volume of wear was that of 3.3 sample $(0.05 \mathrm{wt} . \% \mathrm{SiC})$. Under the highest load equal to $300 \mathrm{~N}$, the amount of resistance of 3.3 was only $23 \%$ of the volume of wear of non-modified sample 3.1 .
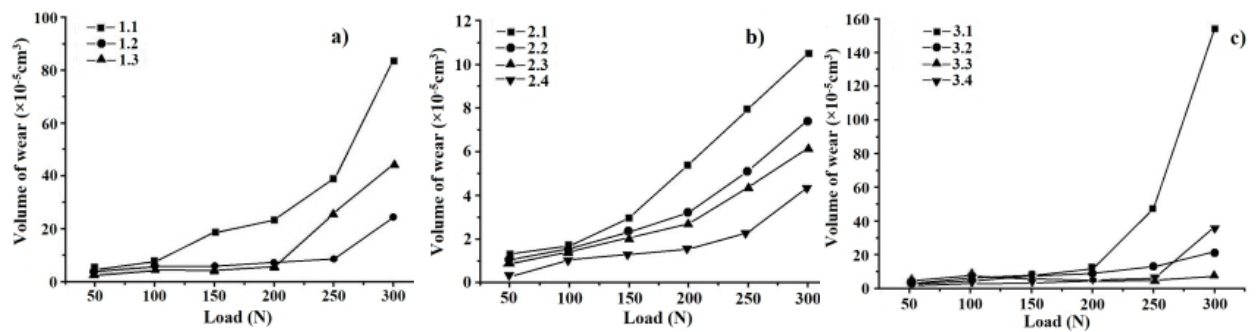

Fig. 3. Relations between the volume of wear and the load for cast iron samples with different $\mathrm{SiC}$ content: a) GG-15; b) GG-25; c) GGG-50.

SEM of worn surfaces. The surfaces of cast iron samples GG-15 and GGG-50 with different $\mathrm{SiC}$ content, subjected to wear with abrasive particles under the load of $250 \mathrm{~N}$, are shown in Fig. 4. For GG-15 (Fig. $4 a, b$ ), the traces of the wear of initial sample 1.1 (Fig. $4 a$ ) were deeper and wider than those for the modified sample 1.2 (Fig. $4 b$ ). In addition, elongated accumulations appeared on the surface of 1.1 , while this phenomenon was not seen on sample 1.2. Many deeper and wider paths appeared on the surface of non-modified GGG-50 (Fig. 4c, sample 3.1), while the surface of modified sample 3.3 (Fig. 4d) was very smooth with evident relief strips.
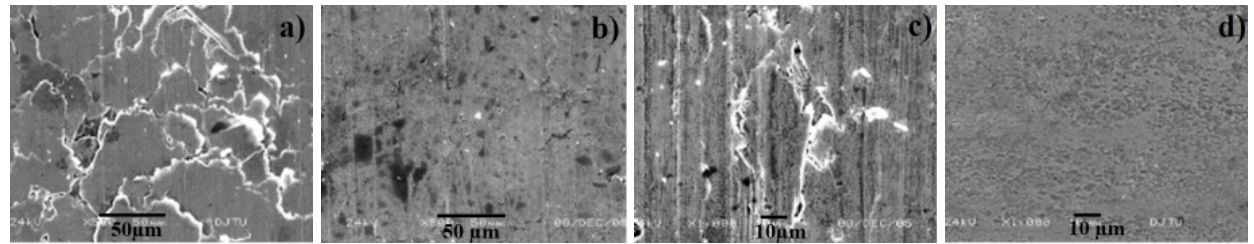

Fig. 4. Morphology of worn-out surfaces of cast iron samples with different $\mathrm{SiC}$ content (wt.\%): GG-15 - a) 0; b) 0.1; GGG-50 - c) 0; d) 0.05 .

For $\mathrm{SiC}$ particles to be able to alter the characteristics of a material, they should be wetted with this material [7], and distributed in metal volume uniformly and rapidly. Modifiers of this kind may be obtained through treatment in high-energy activator mills. The introduction of $\mathrm{SiC}$ as heterogeneous seeding additive into cast iron affects the temperature of melt supercooling, which leads to the formation of mainly perlite structure in gray cast iron [6] and, as a consequence, causes an increase in strength, hardness and wear resistance.

Modified cast iron samples with spheroidal graphite exhibit smaller radius and better rounded shape along with more uniform distribution of spheroidal graphite [6], which promotes a decrease in damage caused by strain concentration, and increase in matrix integrity in wear resistance tests. Increased impact viscosity due to the higher ferrite content in the modified sample provides larger space for matrix deformation under normal load, and the deformed matrix may compensate for pores caused by dropping out spheroidal graphite, which allows avoiding the formation of scratches. 


\section{Conclusions}

The short-term mechanochemical treatment allows producing the composite modifiers that are wetted by the cast iron melt and effectively influence the processes of crystallization. Modifiers based on silicon carbide with metal-protector (chromium) change the ratio of ferrite and perlite.

The introduction of $\mathrm{SiC}$ in the amount of $0.01-0.1 \mathrm{wt} . \%$ into gray cast iron causes the formation of mainly perlitic structure and, as a consequence, an increase in strength, hardness and wear resistance. For $\mathrm{SiC}$ content $0.1 \mathrm{wt} . \%$, the tensile strength of GG-15 samples increased by $22.7 \%$, GG- 25 by $8 \%$. The maximal increase in the hardness is observed for SiC concentration: for GG-15 - 0.1, for GG-25 - 0.01 wt.\%. The GG-25 sample with $0.1 \mathrm{wt} . \% \mathrm{SiC}$ exhibited the highest wear resistance.

The introduction of $\mathrm{SiC}$ (0.01-0.1 wt.\%) into cast iron with spheroidal graphite causes an increase in ferrite content, which promotes a substantial increase in impact viscosity and wear resistance (the highest wear resistance is observed with the introduction of $0.05 \mathrm{wt} . \%$ $\mathrm{SiC})$.

\section{References}

1. A.N. Zadiranov, A.M. Katz, Theoretical bases of crystallization of metals and alloys. M.: Publishing House of the Peoples' Friendship University of Russia, 2007. 228 p. [in Russian].

2. A.L. Greer, J. Chem. Phys. 145, 11704 (2016)

3. Y. Hou, Y. Wang, Z. Pan, L. Yu, J. Rare Earths, 30, 283 (2012)

4. R. Dimitrova, P. Kuzmanov, R. Lazarova, V. Manolov, Adv. Mat. Res. 629, 284 (2013)

5. A.N. Cherepanov, V. Manolov, V.A. Poluboyarov, V.O. Drozdov, Tyazheloe Mashinostroenie [Heavy Engineering], 8, 8 (2012) [in Russian].

6. V.A. Poluboyarov, A.N. Cherepanov, Z.A. Korotaeva, A.A. Zhdanol, V.A. Kuznetsov, Modification of gray and high-strength cast iron with silicon carbide compositions, in Proceedings of the $6^{\text {th }}$ Russian-Kazakhstan Scientific and Practical Conference "Chemical Technologies of Functional Materials", 15-16 June, 2020, Almaty, Kazakhstan (2020)

7. L.I. Mirkin, Physical foundations of strength and plasticity (an Introduction into the theory of dislocations) (Moscow, MGU, 1968) 